\title{
Sialylation and glycosylation modulate cell adhesion and invasion to extracellular matrix in human malignant lymphoma: Dependency on integrin and the Rho GTPase family
}

\author{
OSAMU SUZUKI, MASAFUMI ABE and YUKO HASHIMOTO
}

Department of Diagnostic Pathology, School of Medicine, Fukushima Medical University, Fukushima 960-1295, Japan

Received August 5, 2015; Accepted September 30, 2015

DOI: $10.3892 /$ ijo.2015.3211

\begin{abstract}
To determine the biological roles of cell surface glycosylation, we modified the surface glycosylation of human malignant lymphoma cell lines using glycosylation inhibitors. The O-glycosylation inhibitor, benzyl- $\alpha$-GalNAc (BZ) enhanced the fibronectin adhesion of HBL-8 cells, a human Burkitt's lymphoma cell line, and of H-ALCL cells, a human anaplastic large cell lymphoma cell line, both of which were established in our laboratory. The $\mathrm{N}$-glycosylation inhibitor, tunicamycin (TM) inhibited the surface expression of Phaseolus vulgaris leukoagglutinating (L-PHA) lectin- and Canavalia ensiformis (ConA) lectinreactive oligosaccharides in the HBL-8 cell line. Assay of the adhesion of HBL- 8 cells to fibronectin showed that fibronectin adhesion is mediated by the integrin very late antigen (VLA)-4 and that not only BZ but also TM treatment enhanced HBL-8 cell adhesion to fibronectin. Furthermore, although BZ treatment also enhanced H-ALCL cell adhesion to fibronectin, this effect was not mediated by VLA-5 or the RGD sequence of fibronectin. We also showed that H-ALCL cell adhesion to galectin-3 was enhanced by pre-treatment with neuraminidase, which cleaves cell surface sialic acid. Additionally, H-ALCL cell adhesion to galectin-3 was inhibited by pre-treatment with the RGD peptide suggesting that cell adhesion to galectin-3 is mediated by integrin (VLA-5). Furthermore, H-ALCL cell invasion of galectin-1 and galectin-3 was inhibited by pre-treatment with the RGD peptide. Therefore, cell adhesion to and invasion of galectin-1 and galectin-3 are integrin-dependent. In addition to these findings, cell adhesion to galectin-3 was markedly inhibited by treatment with $\beta$-lactose compared to treatment with sucrose.
\end{abstract}

Correspondence to: Dr Osamu Suzuki, Department of Diagnostic Pathology, School of Medicine, Fukushima Medical University, 1 Hikarigaoka, Fukushima 960-1295, Japan

E-mail: osuzuki@fmu.ac.jp

Key words: glycosylation inhibitors, N-linked glycosylation, O-linked glycosylation, sialic acid, cell adhesion, extracellular matrix, integrin, RGD peptide, Rac 1, Cdc42, Rho
Therefore, interactions between integrins and galectin-3 may be mediated through $\beta$-galactose that is linked to glycans of integrins. AZA1, an inhibitor of Ras homolog oncoprotein (Rho) GTPase family proteins, RAS-related C3 botulinus toxin substrate 1 (Rac 1) and Cell division control protein 42 homolog (Cdc42) markedly inhibited cell invasion of galectin-1 and galectin-3 suggesting that Rac 1 and $\mathrm{Cdc} 42$ may be involved in the regulation of H-ALCL cell invasion of galectins. In conclusion, artificial modification of cell surface glycosylation revealed the biological roles of glycosylation in the adhesion to and invasion of the extracellular matrix (ECM) by human malignant lymphoma cell lines. These findings will provide new insight into the glycobiology of human malignant lymphoma.

\section{Introduction}

Glycosylation of human malignant lymphoma cells is known to be closely associated with the patient clinical outcome $(1,2)$. We speculated that cell surface glycans may play an important role in lymphoma cell behavior. In a recent study we showed that loss of cell surface Peanut agglutinin (PNA) reactive oligosaccharides is closely associated with a poor prognosis of patients with Burkitt's lymphoma (3). Cell surface O-linked oligosaccharides play an important role in cell adhesion (4-6) or galectin-induced cell death (7).

We also previously showed that loss of cell surface L-PHA reactive oligosaccharides or ConA reactive oligosaccharides is also closely associated with a poor prognosis of patients with Burkitt's lymphoma (3). Several studies have suggested that remodeling of the cell surface $\mathrm{N}$-linked oligosaccharides of various cell lines can regulate cell adhesive properties to the extracellular matrix $(\mathrm{ECM})(8,9)$. We previously reported that alteration of $\mathrm{N}$-linked oligosaccharides by treatment of cells with the glycosylation inhibitor swainsonine (SW) resulted in enhancement of lymphoma cell adhesion to galectin-1 (10).

In the present study we analyzed whether treatment with the O-glycosylation inhibitor BZ, the N-glycosylation inhibitors, swainsonine (SW) or TM, or with an enzyme that cleaves sialic acid, neuraminidase, might influence adhesion to the ECM of cells of a Burkitt's lymphoma and an anaplastic large cell lymphoma cell line. The biological significance of cell surface oligosaccharides associated with $\beta 1$-integrin mediated lymphoma cell adhesion to the ECM is discussed. 
VLA-1

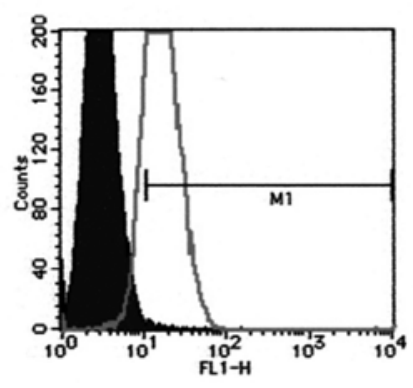

VLA-2

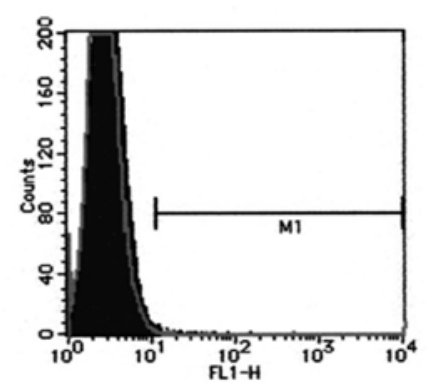

VLA-3

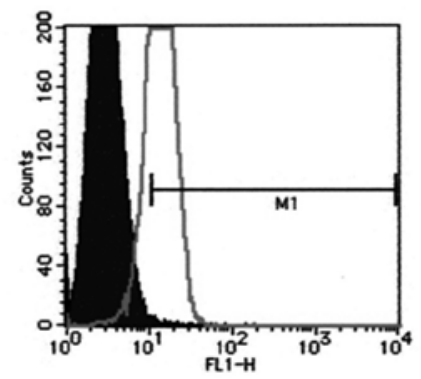

VLA-4

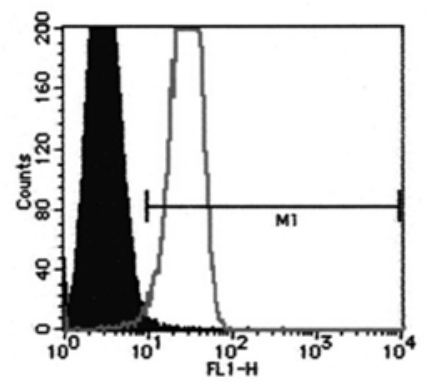

VLA-5

Figure 1. Cell surface expression of VLA integrins. The expression of the integrins VLA-1 to VLA-5 on the surface of HBL-8 $3 \mathrm{G} 3$ cells was analyzed using flow cytometry. The filled area is a control experiment, and the thick line indicates VLA expression. The data shown are representative of two independent experiments.

\section{Materials and methods}

Cell lines. The HBL-8 cell line was established in our laboratory from a patient who had Burkitt's lymphoma (10). The human anaplastic large cell lymphoma cell line, H-ALCL, was also established in our laboratory from a patient. HBL-8 cells (clone, 3G3) and H-ALCL cells were grown in RPMI-1640 culture medium containing $15 \%$ fetal calf serum, under $5 \% \mathrm{CO}_{2}$ at $37^{\circ} \mathrm{C}$. Flow cytometric analysis indicated that the H-ALCL cell line expresses the galectin-1 receptors, CD45RA (leukocyte common antigen, LCA) and CD45RO (UCHL-1) (data not shown). The use of these two cell lines that were derived from patients was approved by the Bioethics Committee of Fukushima Medical University. The informed consent was obtained by disclosure of research concept on Web site Home Page in Fukushima Medical University.

Reagents. The biotinylated lectins, Arachis hypogaea (PNA; BA-2301-2), Phaseolus vulgaris (L-PHA; BA-1801-2), Canavalia ensiformis (ConA; BA-1104-5 and Helix Pomatia (HPA; BA-3601-1) were purchased from EY Laboratories (San Mateo, CA, USA). Anti-VLA-1 antibody, clone 5E8D9, was from Upstate Biotechnology (NY, USA). Anti-VLA-2 antibody, clone AK-7, and anti-VLA-3 antibody, clone C3 II.1 were from BD Pharmingen (USA). Anti-VLA-4 antibody, clone HP2/1, was from Immunotech, a Beckman Coulter Co. (France). Anti-VLA-5 antibody, clone NKI-SAM-1, was from Chemicon International (USA). Anti-CD45 antibody (leukocyte common antigen, LCA) was from Nichirei, H0408, Japan.

Flow cytometric analysis. In brief, $5 \times 10^{5}$ cells of the HBL-8 3G3 cloned cell line were suspended in $100 \mu 1$ phosphate-buffered saline (PBS), and incubated with $5 \mu \mathrm{l}$ biotinylated lectins or anti-VLA monoclonal antibodies at $4{ }^{\circ} \mathrm{C}$ for $20 \mathrm{~min}$ and, then washed twice with PBS. The cells were then incubated with $5 \mu \mathrm{l}$ avidin-FITC (Vector Laboratories, Inc., Burlingame, CA, USA) at $4^{\circ} \mathrm{C}$ for $20 \mathrm{~min}$ or with $5 \mu 1$ fluorescein conjugated anti-mouse immunoglobulin (\#AMI 4408, BioSource International Inc., CA, USA) at $4^{\circ} \mathrm{C}$ for $20 \mathrm{~min}$, and were subsequently washed twice with PBS, following which fluorescence intensity was analyzed using a FACScan.

For inhibition of O-linked oligosaccharides, $5 \times 10^{6}$ HBL-8 3G3 cloned cells were incubated at $37^{\circ} \mathrm{C}$ in $20 \mathrm{ml}$ RPMI-1640 containing 15\% FCS with or without $2 \mathrm{mM} \mathrm{BZ}$ for $48 \mathrm{~h}$ before flow cytometric analysis using biotinylated HPA lectin. For inhibition of N-glycans, 1x10 $70^{7} \mathrm{HBL}-83 \mathrm{G} 3$ cloned cells were incubated at $37^{\circ} \mathrm{C}$ in $20 \mathrm{ml}$ RPMI-1640 containing $15 \%$ FCS with or without $0.1 \mu \mathrm{g} / \mathrm{ml} \mathrm{SW}$ or with or without $1.0 \mu \mathrm{g} / \mathrm{ml} \mathrm{TM}$ for $24 \mathrm{~h}$ before flow cytometric analysis using biotinylated L-PHA, ConA or PNA lectins.

Cell adhesion assay. The 96-well tissue culture plates were coated with the matrix protein fibronectin $(4305-\mathrm{FN}, \mathrm{R} \& \mathrm{D}$ Systems, USA: 0.5, 1.0 and $1.5 \mu \mathrm{g} /$ well), human recombinant galectin-1 (10 $\mu \mathrm{g} /$ well, ATGP0385, ATGen Co. Ltd., USA) and galectin-3 (2 $\mu \mathrm{g}$ /well, PROSPEC, CYT-606, Funakoshi, Japan), and were dried at room temperature overnight. Each well was filled with $100 \mu$ 1 PBS solution and the PBS was then removed by aspiration. Each well was filled with RPMI-1640 culture medium containing $15 \%$ BSA and $15 \%$ FCS, and was cultured at $37^{\circ} \mathrm{C}$ for $60 \mathrm{~min}$. After aspiration of the medium, HBL-8 or H-ALCL cells (100 $\mu \mathrm{l}$ from the cell density at $1 \times 10^{6} / 2 \mathrm{ml}$ ) were added to each well and were incubated at $37^{\circ} \mathrm{C}$ for 1 or $2 \mathrm{~h}$. After aspiration of the medium, PBS solution was added to each well and the PBS was then aspirated to remove non-adhered cells. Subsequently, $100 \mu \mathrm{l}$ of $3.7 \%$ 
formaldehyde was added to each well to fix the adhered cells, and was incubated at RT for $40 \mathrm{~min}$. After aspiration of the formaldehyde, $100 \mu \mathrm{l}$ of $0.1 \%$ crystal violet was added to each well and the plates were incubated at RT for $40 \mathrm{~min}$. After aspiration of the crystal violet, $200 \mu \mathrm{l}$ of PBS was added to each well and then removed by aspiration. Subsequently, $100 \mu 1$ of $10 \%$ acetic acid was added to each well and the absorbance at 570-655 or $570 \mathrm{~nm}$ was determined using an ELISA plate reader (iMark ${ }^{\mathrm{TM}}$, Microplate Reader, Bio-Rad, Hercules, CA, USA) (10). The capacity of the cells to adhere to the extracellular matrix was evaluated by analysis of the absorbance in tested wells.

To confirm the $\beta 1$-integrin-dependency of cell adhesion, inhibition assays were performed by pre-incubation of the cells with $2 \mu \mathrm{g}$ isotype control Ab/100 $\mu \mathrm{l}$ PBS for $1 \mathrm{~h}$ (purified mouse IgG, $\kappa$ isotype, cat no. 555746, BD Pharmingen, Japan), $2 \mu \mathrm{g}$ anti-VLA-4 antibody/100 $\mu \mathrm{l} \mathrm{PBS}$ for $1 \mathrm{~h}$ (HP2/1, no. 0764 , Immunotech, A Coulter Co.), $2 \mu \mathrm{g}$ ant-VLA-5 antibody/100 $\mu \mathrm{l}$ PBS for $1 \mathrm{~h}$ (MAB1986, Chemicon), $1 \mu \mathrm{g} / \mu \mathrm{l}$ Fibronectin CS-1 peptide for $1 \mathrm{~h}$ (GWB-B6016B, GenWay Biotech. Inc. San Diego, CA, USA) or with $1 \mu \mathrm{g} / \mu \mathrm{l}$ Fibronectin RGD peptide for $1 \mathrm{~h}$ (A8052; Sigma, Japan) prior to the fibronectin or galectin adhesion assay.

For inhibition of O-linked oligosaccharides, $5 \times 10^{6}$ HBL-8 3G3 cloned cells were incubated at $37^{\circ} \mathrm{C}$ in $20 \mathrm{ml}$ RPMI-1640 containing 15\% FCS with or without $2 \mathrm{mM} \mathrm{BZ}$ for $48 \mathrm{~h}$ before the adhesion assay. For inhibition of $\mathrm{N}$-glycans, $1 \times 10^{7} \mathrm{HBL}-83 \mathrm{G} 3$ cloned cells were incubated at $37^{\circ} \mathrm{C}$ in $20 \mathrm{ml}$ RPMI-1640 containing $15 \%$ FCS with or without $0.1 \mu \mathrm{g} / \mathrm{ml}$ SW for $24 \mathrm{~h}$ before the adhesion assay; or $5 \times 10^{6} \mathrm{HBL}-83 \mathrm{G} 3$ cloned cells were incubated at $37^{\circ} \mathrm{C}$ in $20 \mathrm{ml} \mathrm{RPMI}-1640$ containing $15 \%$ FCS with or without $1.0 \mu \mathrm{g} / \mathrm{ml} \mathrm{TM}$ for $24 \mathrm{~h}$ before the adhesion assay.

To analyze the role of cell surface sialic acid in cell adhesion to galectin, H-ALCL cells were pre-treated with or without $0.2 \mathrm{U} / \mathrm{ml}$ neuraminidase from Arthrobacter ureafaciens (no. 10269611001, Roche, Germany) at $37^{\circ} \mathrm{C}$ for $30 \mathrm{~min}$ before the adhesion/invasion assay. To analyze the geta-galactose dependency, the cell adhesion assay to galectins was performed with $0.1 \mathrm{M} \beta$-lactose, and in the control, with $0.1 \mathrm{M}$ sucrose.

Invasion assay. The invasion assay (haptotaxis) was performed as reported (12) with several modifications. The 24-well culture plate was filled with $600 \mu$ l the culture medium RPMI-1640 containing $15 \%$ BSA $15 \%$ FCS. The lower surfaces of the membranes of transwell chamber, chemotaxicell (Krabo, Japan) witrh $8-\mu \mathrm{m}$ pore membrane were coated with $10 \mu \mathrm{l}$ galectin-1, galectin-3 or galectin- 8 and dried at RT. Then coated chemotaxicells were inserted into each well. In total $100 \mu \mathrm{l}$ of $3 \times 10^{6} / \mathrm{ml} \mathrm{H}$-ALCL cells was inserted into each chemotaxicell and incubated at $37^{\circ} \mathrm{C}$ for $24 \mathrm{~h}$. After incubation, the invaded cells in the lower surfaces of each well were counted by trypanblue exclusion methods. The cell count was performed using triplicate wells $(n=3)$. To evaluation of effect of AZA1, the cells were pre-incubated with $25 \mu \mathrm{M}$ AZA1, for $1 \mathrm{~h}$.

Statistical analysis. The p-values in the experimental results were calculated based on Student's t-test. $\mathrm{p}<0.05$ was considered statistically significant. Data analysis was performed using Microsoft Office Excel 2007.


C


Figure 2. Effect of alteration of cell surface O- or N-linked oligosaccharides on lectin reactivity. Effect of inhibition of glycosylation in the HBL-8 $3 \mathrm{G} 3$ cloned cells on their surface lectin reactivity was analyzed using FACS analysis. (A) HPA lectin reactivity without (thick line) or with (dotted line) BZ treatment. (B) L-PHA or ConA reactivity without (thick dotted line) or with (thin dotted line) SW treatment. (C) L-PHA or ConA reactivity without (thick dotted line) or with (thin dotted line) TM treatment. The filled area is the control experiment with avidin-FITC only. Data shown are representative of two independent experiments.

\section{Results}

Cell surface expression of VLA integrins. Flow cytometric analysis indicated that the integrins VLA-1, -3 and -4 were expressed on the cell surface of HBL-8 3G3 cloned cells, but that VLA-2 and -5 were not expressed (Fig. 1). Previous immunohistochemical findings showed that the H-ALCL cells express VLA-5, but not VLA-4 (11).

Effect of alteration of cell surface $O$ - and $N$-glycans on cell lectin reactivity. Flow cytometric analysis of HBL-8 3G3 cells indicated that the HPA lectin reactivity of the cells increased after inhibition of O-glycosylation with BZ treatment (Fig. 2A). Following inhibition of N-glycosylation with SW treatment the L-PHA reactivity of the cells decreased and the ConA reactivity of the cells increased (Fig. 2B). On the other hand after inhibition of $\mathrm{N}$-glycosylation with TM treatment both the L-PHA reactivity and the ConA reactivity of the cells decreased (Fig. 2C). Our recent report showed that L-PHA reactivity of H-ALCL cells also decreased after TM treatment 


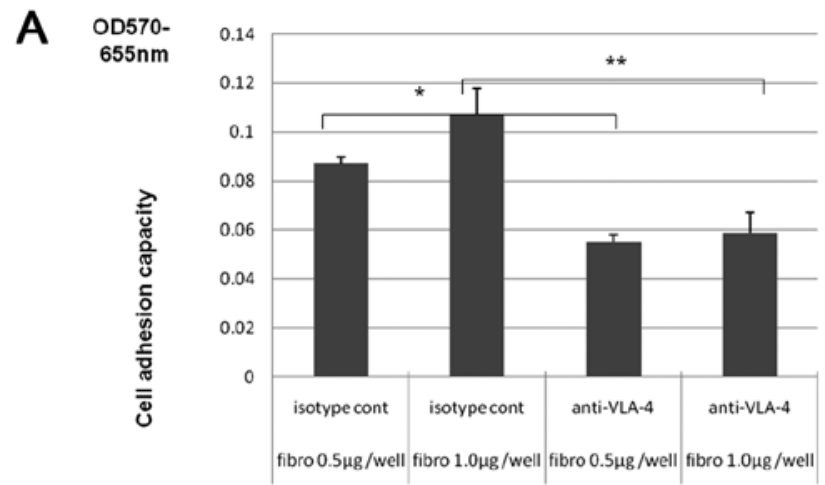

B1

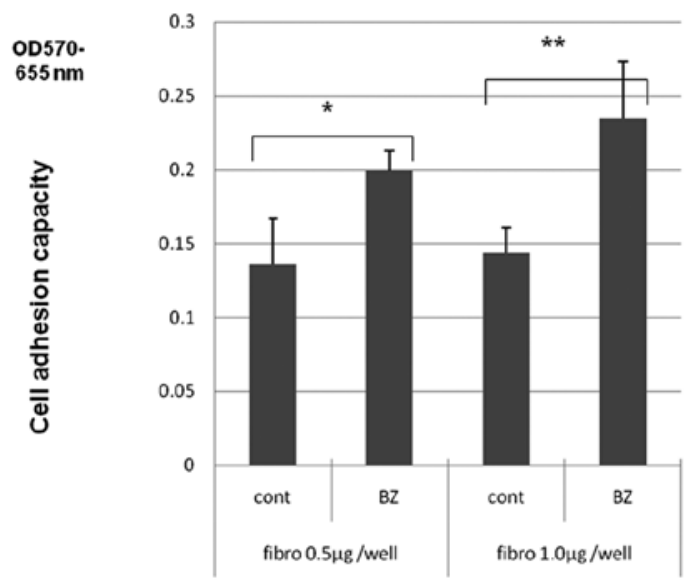

C



B2

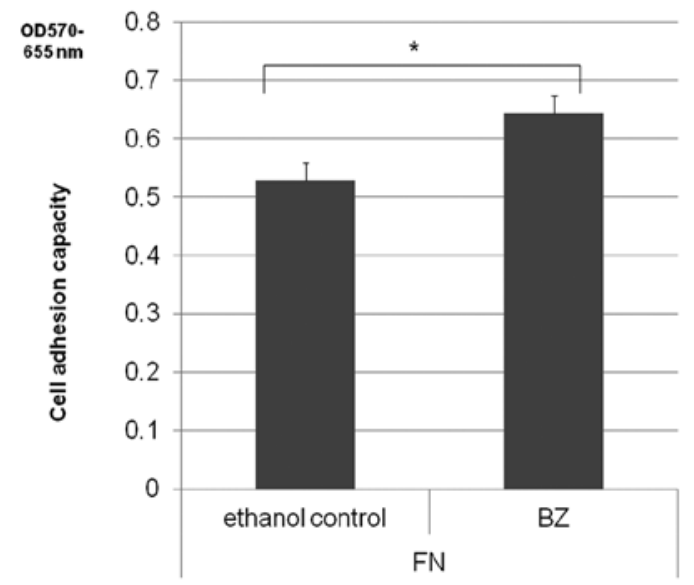

D



Figure 3. Effect of alteration of cell surface glycosylation on cell adhesion to fibronectin. The adhesion of cells to fibronectin, and the effect of anti-VLA-4 antibodies or alteration of cell surface glycosylation on this adhesion were assayed using fibronectin coated culture plates. Adhesion was monitored by measurement of absorption at 570-655 nm. (A) Effect of anti-VLA-4 or isotype control (cont) antibodies on HBL-8 $3 \mathrm{G} 3$ cloned cell adhesion to plates coated with the indicated concentrations of fibronectin (fibro) ( $\mathrm{p}=0.0003,{ }^{* *} \mathrm{p}=0.0035$ ). (B) Effect of BZ or control (cont) treatment on adhesion to fibronectin (fibro) of HBL-8 $3 \mathrm{G} 3$ cells $(\mathrm{B}-1)\left({ }^{*} \mathrm{p}=0.0327,{ }^{* *} \mathrm{p}=0.0194\right)$ or of H-ALCL cells $(\mathrm{B}-2)\left({ }^{*} \mathrm{p}=0.004\right)$. Data shown are representative of two independent experiments performed in triplicate. (C) Effect of SW or control (cont) treatment on adhesion to fibronectin (fibro) of HBL-8 $3 \mathrm{G} 3$ cells (NS, not significant). Data shown are representative of three independent experiments performed in triplicate. (D) Effect of TM or control (cont) on HBL-8 $3 \mathrm{G} 3$ cloned cell adhesion to fibronectin $\left({ }^{*} \mathrm{p}=0.0136,{ }^{* *} \mathrm{p}=0.0010\right.$, ${ }^{* * *} \mathrm{p}=0.0126$ ). Data shown are representative of two independent experiments performed in triplicate. p-values were calculated based on Student's t-test.

(11). These data show that inhibition of O- and N-glycosylation specifically altered cell surface lectin reactivity.

Effect of alteration of cell surface glycosylation on cell adhesion to fibronectin. A fibronectin-coated cell adhesion assay showed that HBL-8 lymphoma cells adhered to fibronectin. Pre-treatment of the cells with anti-VLA-4 or control antibodies indicated that this adhesion was mediated by the integrin VLA-4 (Fig. 3A). The number of HBL-8 $3 \mathrm{G} 3$ or $\mathrm{H}$-ALCL cells that adhered to fibronectin increased following BZ treatment compared to the number of adhered cells in the absence of BZ treatment [Fig. 3B-1 (HBL-8 3G3) and B-2 (H-ALCL)]. There was no significant difference in the number of HBL-8 3G3 cells that adhered to fibronectin between 


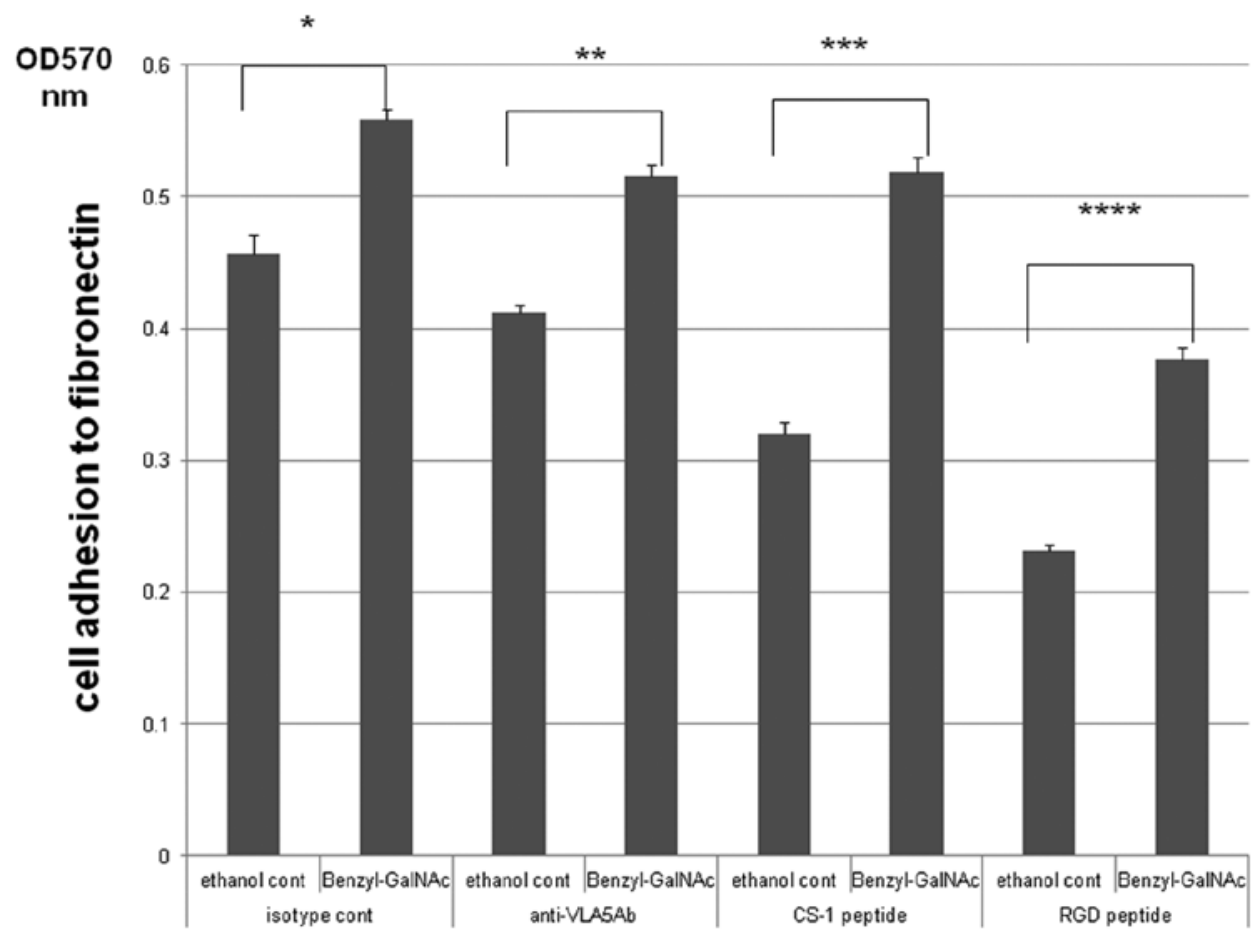

Figure 4. BZ enhancement of H-ALCL cell adhesion to fibronectin is not mediated by VLA-5, or by CS-1 or RGD sequences. H-ALCL cells that were treated with BZ or with ethanol control were incubated with anti-VLA-5 or control antibodies (Ab) or with the CS-1 or RGD peptides and fibronectin adhesion was then assayed as in Fig. $3\left({ }^{*} \mathrm{p}=0.001,{ }^{* *} \mathrm{p}=0.00006,{ }^{* * * *} \mathrm{p}=0.00001,{ }^{* * * *} \mathrm{p}=0.0001\right)$. The data shown are representative of two independent experiments performed in triplicate. p-values were calculated based on Student's t-test.

A

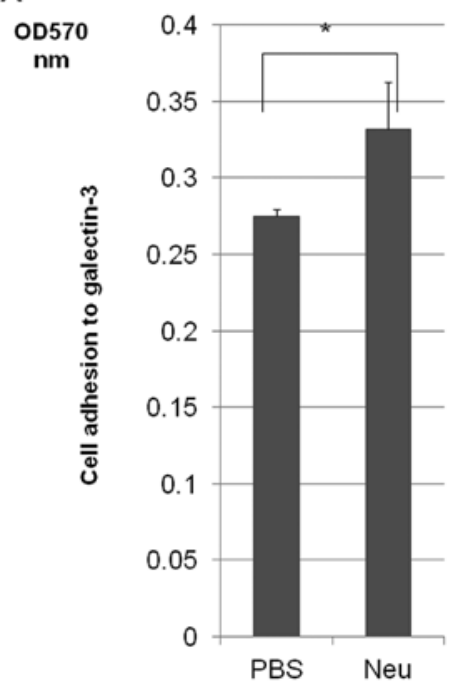

B

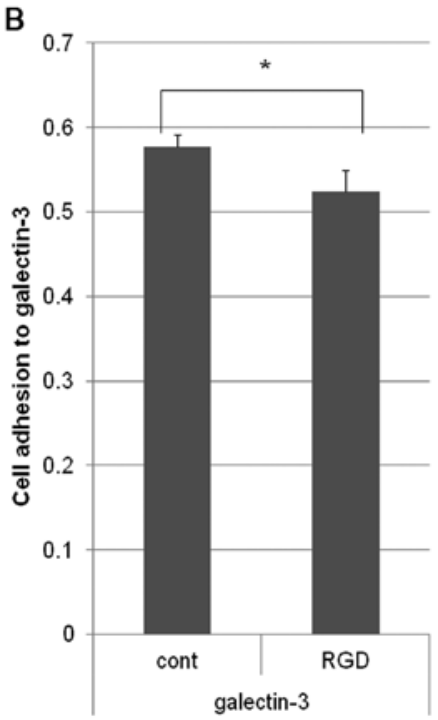

Figure 5. Effect of neuraminidase treatment and the RGD sequence on galectin binding of H-ALCL cells. Cell adhesion to galectin-coated plates was analyzed by determination of the OD at $570 \mathrm{~nm}$ in an adhesion assay. (A) The effect of pre-treatment of H-ALCL cells with neuraminidase on cell adhesion to galectin-3 was analyzed ( ${ }^{*} \mathrm{p}=0.039$ ). (B) The effect of pre-treatment of cells in serum-free medium with the RGD peptide (RGD) or with PBS control (cont) on H-ALCL cell adhesion to galectin-3 was analyzed $\left({ }^{*} \mathrm{p}=0.02\right)$. Data are representative of two independent experiments performed in triplicate.

non-treated and SW-treated cells (Fig. 3C). On the other hand treatment with TM enhanced HBL-8 $3 \mathrm{G} 3$ cell adhesion to fibronectin compared to non-treated cells (Fig. 3D). Thus, alteration of cell surface glycosylation modulates cell adhesion to fibronectin. The enhancement of H-ALCL adhesion to fibronectin by BZ was not mediated by the integrin VLA-5, or by CS-1 or RGD protein sequences (Fig. 4).
Effect of alteration of cell surface glycosylation on $H-A L C L$ cell adhesion to galectins. H-ALCL cells also adhered to galectin-3 and this adhesion to galectin-3 was enhanced by cleavage of cell surface sialic acids by pre-treatment with neuraminidase (Fig. 5A). Furthermore, H-ALCL cell adhesion to galectin-3 was inhibited by RGD peptide pre-treatment (Fig. 5B), with serum-free medium. The ability of H-ALCL 
A

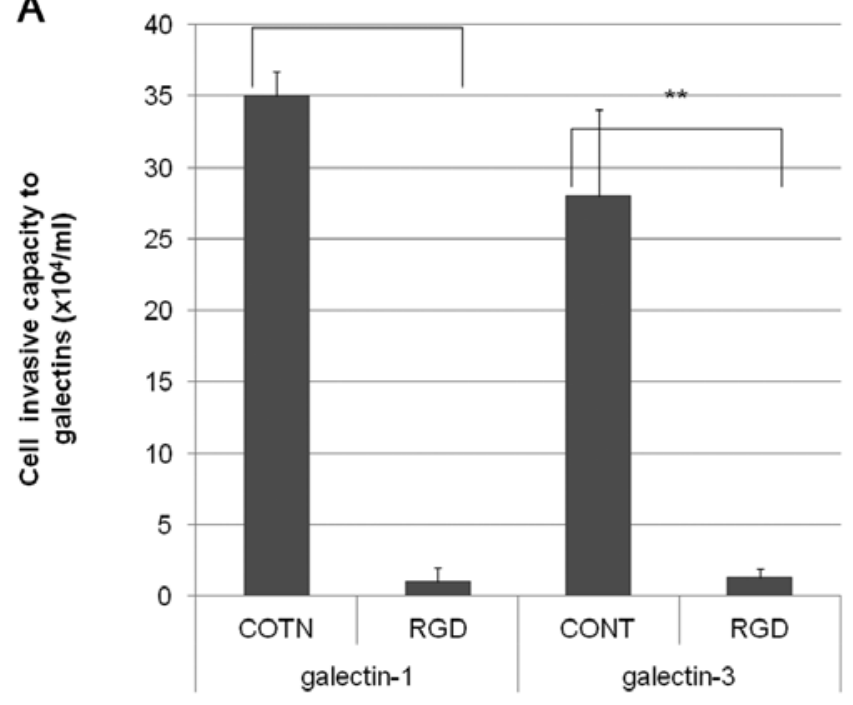

B

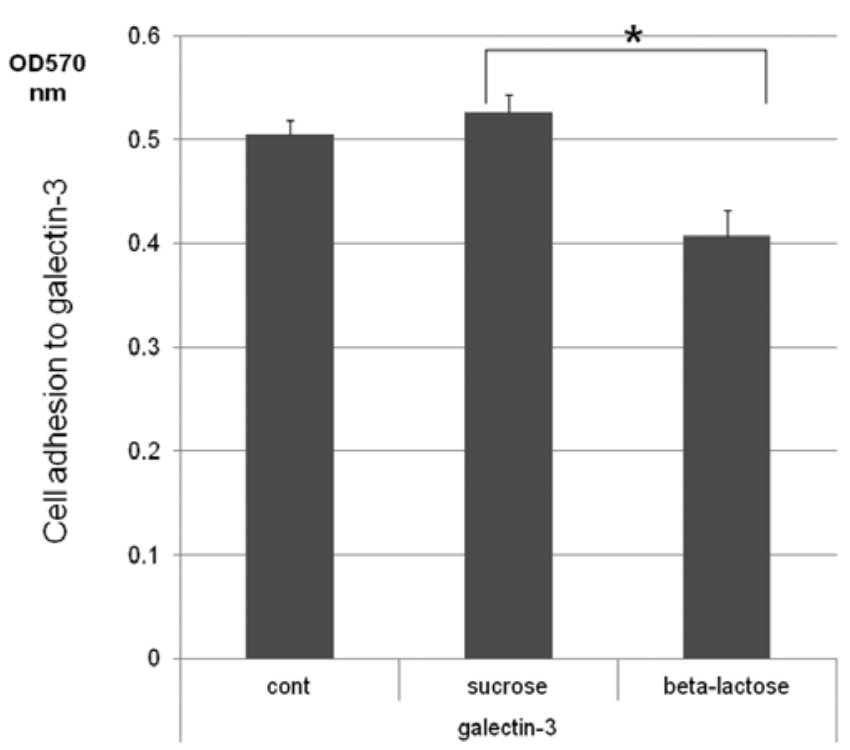

Figure 6. Further analysis of the mechanism of H-ALCL interaction with galectin. (A) Effect of pre-treatment with the RGD peptide (RGD) or PBS control (cont) for $48 \mathrm{~h}$ on H-ALCL cell invasion of galectin-1 and galectin-3 $\left(\mathrm{p}=0.00002,{ }^{* *} \mathrm{p}=0.008\right)$. Data are representative of two independent experiments performed in triplicate. (B) Effect of pre-incubation with $\beta$-lactose, sucrose or control (cont) on H-ALCL cell adhesion to galectin-3 $\left({ }^{* * *} \mathrm{p}=0.001\right)$. cells to invade galectin-1 and galectin-3 was markedly inhibited by pre-incubation with the RGD peptide, indicating that this invasion was dependent on the RGD sequence (Fig. 6A). Further inhibition experiments showed that inhibition of H-ALCL cell adhesion to galectin-3 by $\beta$-lactose was much higher compared to inhibition by sucrose suggesting that H-ALCL cell adhesion to galectin-3 might be mediated by $\beta$-galactose on the cell surface (Fig. 6B).

Potential involvement of small GTP proteins in the galectin invasion of H-ALCL cells. Immunohistochemical analysis showed that $\operatorname{Rac} 1$ and $\mathrm{Cdc} 42$ proteins were expressed in the cytoplasm of H-ALCL cells (Fig. 7). Our previous immunohistochemical analysis showed that Rho is also expressed in the cytoplasm of H-ALCL cells and that the Rho inhibitor, C3-transferase, markedly inhibited H-ALCL invasion of galectins (12). Pre-incubation of H-ALCL cells with AZA1, an inhibitor of Rac 1 and Cdc42, also significantly inhibited cell invasion of galectin-1 and galectin-3 (Fig. 8). The combined above data suggested that the small GTPases Rho, Rac 1 and Cdc42 are involved in H-ALCL invasion to galectin.

\section{Discussion}

The ability of cells to adhere to the ECM is known to be closely associated with the metastatic capacity of malignant tumor cells. Alteration of cell surface glycans can modulate the metastatic rate to distant organs. In the present study, using glycoengineering methods we showed a biological role of the surface glycans of malignant lymphoma cells in cell adhesion and cell invasion to extracellular matrix.

The presence of O-glycans and HPA reactive oligosaccharides was demonstrated on HBL-8 cells using flow cytometric analysis. BZ enhanced the expression of HPA reactive oligosaccharides i.e., GalNAc residues. Adhesion of HBL-8 cells to fibronectin was mediated by the VLA-4 adhesion molecule. This fibronectin adhesion of HBL-8 was enhanced by treatment with BZ. It was unclear whether the VLA-4 mediated cell adhesion was directly modified by administration of BZ and we speculate that the effect of BZ may be mediated by a GalNAc epitope that affects the interactions between VLA-4 and fibronectin. Such a candidate GalNAc epitope would be a

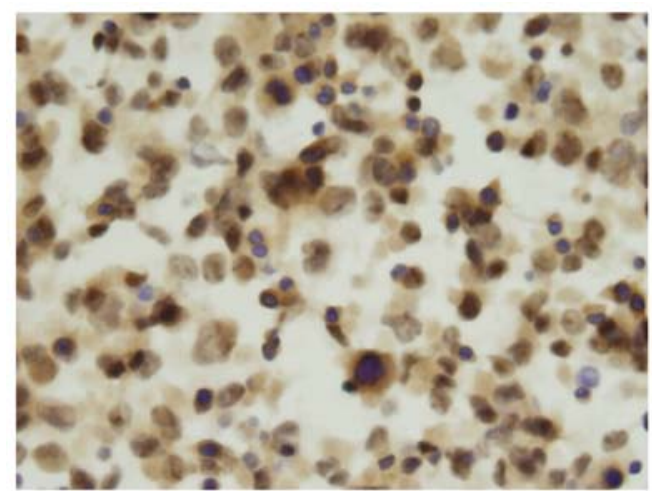

Rac1

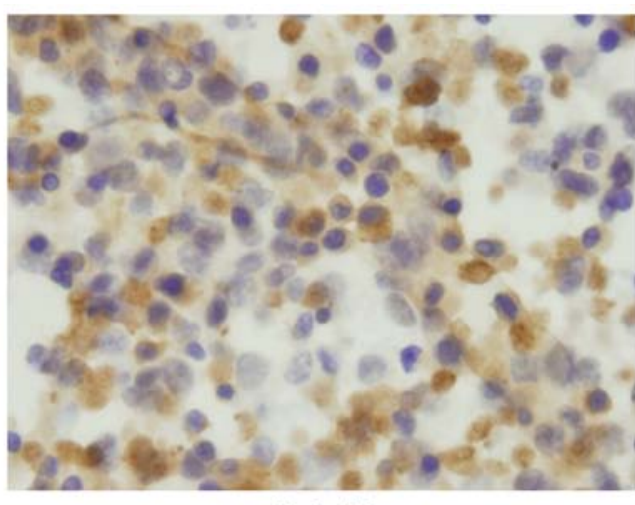

Cdc42

Figure 7. Immunohistochemical analysis of the expression of Rac 1 and Cdc 42 proteins in the cytoplasm of H-ALCL cells. The H-ALCL cells were cytospun onto glass slides and were then fixed by $100 \%$ ethanol. Subsequently, the immunohistochemical staining was performed using standard methods. 


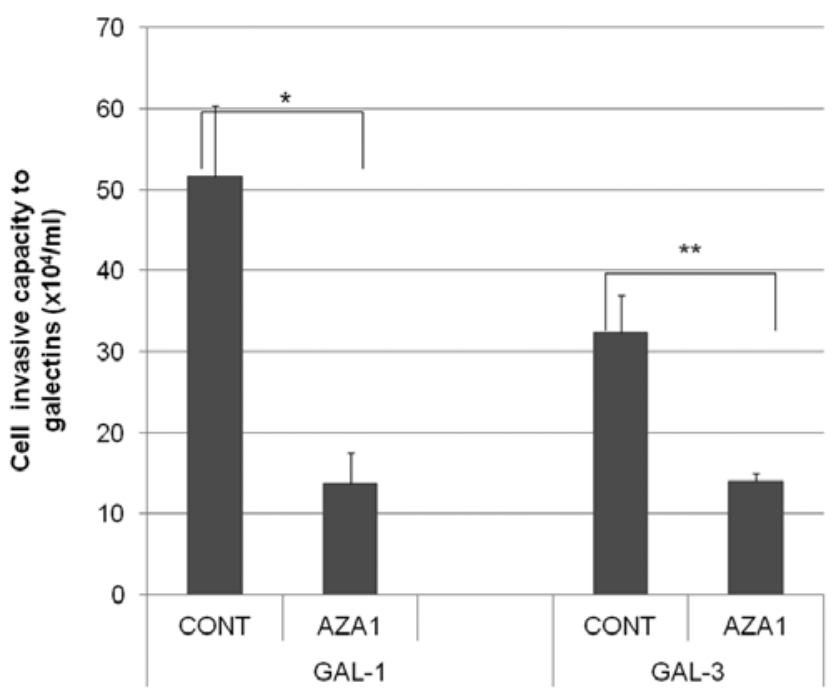

Figure 8. Effect of an inhibitor of Rac 1 and Cdc 42 on H-ALCL cell invasion of galectin-1 and galectin-3. H-ALCL cells were incubated with PBS control (cont) or with the Rac 1 and Cdc42 inhibitor, AZA1, following which cell adhesion to galectin-1 (GAL-1) or galectin-3 (GAL-3) was assayed ( $\mathrm{p}=0.004$, $\left.{ }^{* *} \mathrm{p}=0.008\right)$. Data are representative of two independent experiments that were performed in triplicate.

mucin type epitope, or O-linked oligosaccharides. It is known that $\mathrm{O}$-linked oligosaccharides can influence cell adhesive properties $(4,5,13)$. BZ treatment also enhanced the adhesion of H-ALCL cells to fibronectin. BZ treatment is known to remove sialic acid which is linked to the terminal residue of glycans. Therefore, desialylation of O-glycans by BZ may also enhance cell adhesion to fibronectin. Our present data obtained using H-ALCL cells indicated that this effect is independent of VLA-5 and the RGD sequence of fibronectin. Therefore, the sialic acid on $\mathrm{O}$-glycans may regulate cell adhesion to fibronectin independently of integrins. Previous reports have suggested that desialylation of integrin upregulates cell adhesion to fibronectin (14). On the other hand $\alpha-2,6$ sialic acid has been reported to be required for cell adhesion to fibronectin
(15). In pancreatic carcinoma cells, $\alpha-2,6$ sialic acid is required for tumor cell adhesion to the ECM (16). Based on these findings it appears that there is a difference in the regulation of cell adhesion to the ECM by sialylation among various cell types. Further study will be required to clarify the detailed mechanisms by which sialic acid regulates cell adhesion to the ECM.

CD45 is a candidate receptor for galectin-1 and -3 (17). However, recent data suggest that integrin is also a candidate galectin-3 receptor (18). In our present data, H-ALCL cell adhesion to galectin-3 was inhibited by pretreatment with the RGD peptide suggesting that cell adhesion to galectin-3 was mediated by integrin (VLA-5). Therefore, sialylation may regulate cell adhesion to galectin-3 in an integrin-dependent manner and integrin may act as a galectin receptor in cell adhesion to galectins (Fig. 9). In this model cell adhesion to galectin through integrins would activate intrinsic signals leading to the activation of Rho, Rac 1 and Ccd42, and resulting in rearrangement of the cytoskeleton. These events act as a driving force of cell migration. Therefore, sialic acid may regulate lymphoma cell invasion to galectin through galectin-integrin interaction, subsequently inducing Rho family activation and rearrangement of the cytoskeleton. These phenomena may be associated with lymphoma cell invasion and metastasis.

$\mathrm{N}$-linked oligosaccharides are known to be transferred onto asparagine residues of proteins from a donor substrate, dolichol-phosphate-oligosaccharide, in the endoplasmic reticulum (19). Deglycosylation of glycoproteins that is reflected by a decrease in L-PHA and ConA lectin reactivity may be related to dysfunction of this oligosaccharide transfer to proteins, which is catalyzed by the enzyme oligosaccharyltransferase in the endoplasmic reticulum. The N-glycan inhibitor, SW can inhibit complex type $\mathrm{N}$-glycans, resulting in the expression of hybrid type $\mathrm{N}$-glycans. On the other hand TM can inhibit both complex and hybrid type $\mathrm{N}$-glycan expression. Our data showed that SW cannot enhance cell adhesion to fibronectin, whereas TM can. Therefore, differences in the detail of the $\mathrm{N}$-glycan structures resulting from SW and TM treatments can influence cell adhesion to FN. Not only O-glycans, but also

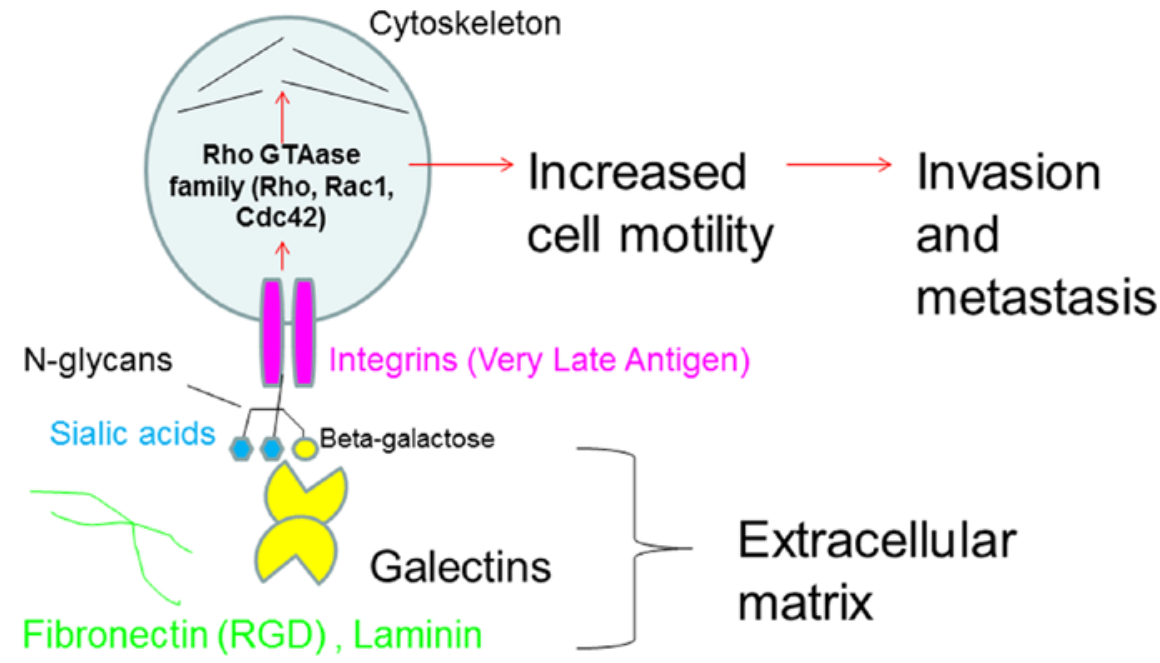

Figure 9. Schematic representation of the biological roles of cell surface glycosylation in human malignant lymphoma cell adhesion to and invasion of the extracellular matrix. 
N-glycans may regulate HBL-8 and H-ALCL cell adhesion to fibronectin. Some previous studies have suggested that alteration of the N-glycosylation of $\beta$-1 integrins may modulate the ability of cells to adhere to the ECM (20). In addition to this, it was suggested that VLA-4 expression may be closely related to the ability of a tumor to metastasize to distant organs in an animal model (21). Therefore, cell surface $\mathrm{N}$-glycans may modulate metastatic capacity by modulation of VLA-4 function in lymphoma cells.

In a previous report we showed that L-PHA reactive N-linked oligosaccharide on the lymphoma cell surface is closely associated with clinical behavior of diffuse large B cell lymphoma (DLBCL) cases $(1,2)$. Loss of L-PHA reactive $\mathrm{N}$-glycans on the cell surface is correlated to a poor prognosis of DLBCL. In the present study TM treatment resulted in enhancement of HBL-8 3G3 lymphoma cell adhesion to fibronectin or in the recent study, inhibition of H-ALCL cell adhesion to fibronectin and laminin (11). $\mathrm{N}$-glycan bidirectionally regulates cell adhesion to fibronectin suggesting that alteration of $\mathrm{N}$-glycans affects cell adhesion to the ECM resulting in modulation of the biological behavior of lymphoma cells. Previous reports showed that TM treatment modulates cell surface glycosylation expression, resulting in alteration of cell adhesion to the ECM (22), and that alteration of cell surface glycosylation affects cell to cell adhesion or cell-matrix interaction in several tumor cell lines $(22,23-26,27,28)$. These findings and our present data may provide a new scientific area of study of tumor cell biology that is focused on the regulation of cell adhesion to the ECM by glycosylation.

GTPases are known to include Rac $1, \operatorname{Cdc} 42$ and Rho. Rac 1 forms lamellipodia, Cdc42 forms filopodia, and Rho forms stress fibers, and these molecules are known to be associated with cancer progression (29). The function of these molecules is associated with cell motility of lymphoma cells that is mediated through galectins in the stroma. Furthermore, sialic acid on the cell surface may regulate cell adhesion to galectins that is mediated by integrins. Sialic acid is adequately regulated on cell adhesion to galectin resulting in facilitation of cell motility, and subsequently enhances cell motility resulting in more aggressive tumor behavior and metastasis. In the present data, cell adhesion to galectin-3 was inhibited by cell surface sialylation suggesting that cell surface sialic acid may regulate cell adhesion to galectins. In terms of cell surface glycosylation, especially of sialylation, we speculate that sialylation enhances Rho GTPase family induced cell invasive capacity and may result in a worse prognosis of the patients. Our present data showed that desialylation enhanced cell adhesion to galectin and inhibited cell invasion to galectin (12), suggesting that the effect of desialylation on cell invasion of galectin is the opposite to the effect of the Rho GTPase family on cell invasion.

In conclusion, cell surface sialylation appeared to be a candidate molecule for the regulation of cell adhesion, and the present data may provide a new scientific focus for lymphoma glycobiology.

\section{Acknowledgements}

We are grateful to Ms. M. Satoh and Mrs. H. Kaneko for their technical assistance and advice.

\section{References}

1. Suzuki O, Nozawa Y, Kawaguchi T and Abe M: Phaseolus vulgaris leukoagglutinating lectin-binding reactivity in human diffuse large B-cell lymphoma and its relevance to the patient's clinical outcome: Lectin histochemistry and lectin blot analysis. Pathol Int 49: 874-880, 1999.

2. Suzuki O, Nozawa Y, Kawaguchi T and Abe M: Alpha-2,6sialylation of L-PHA reactive oligosaccharides and expression of $\mathrm{N}$-acetylglucosaminyltransferase $\mathrm{V}$ in human diffuse large $\mathrm{B}$ cell lymphoma. Oncol Rep 10: 1759-1764, 2003.

3. Suzuki O, Nozawa Y and Abe M: Loss of L-PHA-, PNA-, or ConAreactive oligosaccharides is associated with a poor prognosis in human Burkitt's lymphoma. Oncol Rep 17: 775-779, 2007.

4. Porowska H, Paszkiewicz-Gadek A, Anchim T, Wolczynski S and Gindzienski A: Inhibition of the O-glycan elongation limits MUC1 incorporation to cell membrane of human endometrial carcinoma cells. Int J Mol Med 13: 459-464, 2004.

5. Kojima N, Saito M and Tsuji S: Role of cell surface O-linked oligosaccharides in adhesion of HL60 cells to fibronectin: Regulation of integrin-dependent cell adhesion by O-linked oligosaccharide elongation. Exp Cell Res 214: 537-542, 1994.

6. Paszkiewicz-Gadek A, Porowska H, Lemancewicz D, Wolczynski S and Gindzienski A: The influence of $\mathrm{N}$ - and O-glycosylation inhibitors on the glycosylation profile of cellular membrane proteins and adhesive properties of carcinoma cell lines. Int J Mol Med 17: 669-674, 2006.

7. Suzuki O, Nozawa Y and Abe M: Regulatory roles of altered Nand O-glycosylation of CD45 in galectin-1-induced cell death in human diffuse large B cell lymphoma. Int J Oncol 26: 1063-1068, 2005.

8. Guo HB, Lee I, Kamar M, Akiyama SK and Pierce M: Aberrant $\mathrm{N}$-glycosylation of betal integrin causes reduced alpha5beta1 integrin clustering and stimulates cell migration. Cancer Res 62: 6837-6845, 2002.

9. Zhang Y, Zhao JH, Zhang XY, Guo HB, Liu F and Chen HL: Relations of the type and branch of surface N-glycans to cell adhesion, migration and integrin expressions. Mol Cell Biochem 260: 137-146, 2004.

10. Suzuki O, Nozawa Y and Abe M: The regulatory roles of cell surface sialylation and $\mathrm{N}$-glycans in human B cell lymphoma cell adhesion to galectin-1. Int J Oncol 28: 155-160, 2006.

11. Suzuki O, Abe M and Hashimoto Y: Sialylation by $\beta$-galactoside $\alpha-2,6$-sialyltransferase and $\mathrm{N}$-glycans regulate cell adhesion and invasion in human anaplastic large cell lymphoma. Int J Oncol 46: 973-980, 2015.

12. Suzuki O and Abe M: Galectin-1-mediated cell adhesion, invasion and cell death in human anaplastic large cell lymphoma: Regulatory roles of cell surface glycans. Int J Oncol 44: 1433-1442, 2014.

13. Zhang L and Ten Hagen KG: The cellular microenvironment and cell adhesion: A role for O-glycosylation. Biochem Soc Trans 39: 378-382, 2011.

14. Semel AC, Seales EC, Singhal A, Eklund EA, Colley KJ and Bellis SL: Hyposialylation of integrins stimulates the activity of myeloid fibronectin receptors. J Biol Chem 277: 32830-32836, 2002.

15. Yu S, Fan J, Liu L, Zhang L, Wang S and Zhang J: Caveolin-1 up-regulates integrin $\alpha 2$,6-sialylation to promote integrin $\alpha 5 \beta 1$ dependent hepatocarcinoma cell adhesion. FEBS Lett 587: 782-787, 2013.

16. Bassagañas S, Pérez-Garay $M$ and Peracaula R: Cell surface sialic acid modulates extracellular matrix adhesion and migration in pancreatic adenocarcinoma cells. Pancreas 43: 109-117, 2014.

17. Perillo NL, Pace KE, Seilhamer JJ and Baum LG: Apoptosis of T cells mediated by galectin-1. Nature 378: 736-739, 1995.

18. Zhuo Y, Chammas R and Bellis SL: Sialylation of betal integrins blocks cell adhesion to galectin-3 and protects cells against galectin-3-induced apoptosis. J Biol Chem 283: 22177-22185, 2008 .

19. Kornfeld R and Kornfeld S: Assembly of asparagine-linked oligosaccharides. Annu Rev Biochem 54: 631-664, 1985.

20. Janik ME, Lityńska A and Vereecken P: Cell migration-the role of integrin glycosylation. Biochim Biophys Acta 1800: 545-555, 2010.

21. Matsuura N, Puzon-McLaughlin W, Irie A, Morikawa Y, Kakudo K and Takada Y: Induction of experimental bone metastasis in mice by transfection of integrin alpha 4 beta 1 into tumor cells. Am J Pathol 148: 55-61, 1996. 
22. Kemmner W, Morgenthaler J and Brossmer R: Alterations in cell surface carbohydrate composition of a human colon carcinoma cell line affect adhesion to extracellular matrix components. Biochimie 74: 117-122, 1992.

23. Przybyło M, Pocheć E, Link-Lenczowski P and Lityńska A: Beta1-6 branching of cell surface glycoproteins may contribute to uveal melanoma progression by up-regulating cell motility. Mol Vis 14: 625-636, 2008.

24. Zhao H, Liang Y, Xu Z, Wang L, Zhou F, Li Z, Jin J, Yang Y, Fang $\mathrm{Z}, \mathrm{Hu} \mathrm{Y}$, et al: $\mathrm{N}$-glycosylation affects the adhesive function of E-Cadherin through modifying the composition of adherens junctions (AJs) in human breast carcinoma cell line MDA-MB-435. J Cell Biochem 104: 162-175, 2008.

25. Sato T, Takahashi M, Kawado T, Takayama E and Furukawa K: Effect of staurosporine on N-glycosylation and cell adhesion to fibronectin of SW480 human colorectal adenocarcinoma cells. Eur J Pharm Sci 25: 221-227, 2005.
26. Schraen-Maschke S and Zanetta JP: Role of oligomannosidic $\mathrm{N}$-glycans in the proliferation, adhesion and signalling of $\mathrm{C} 6$ glioblastoma cells. Biochimie 85: 219-229, 2003.

27. Bironaite D, Nesland JM, Dalen H, Risberg B and Bryne M: $\mathrm{N}$-Glycans influence the in vitro adhesive and invasive behaviour of three metastatic cell lines. Tumour Biol 21: 165-175, 2000.

28. de Freitas Junior JC, Silva BR, de Souza WF, de Araújo WM, Abdelhay ES and Morgado-Díaz JA: Inhibition of N-linked glycosylation by tunicamycin induces E-cadherin-mediated cell-cell adhesion and inhibits cell proliferation in undifferentiated human colon cancer cells. Cancer Chemother Pharmacol 68: 227-238, 2011.

29. Rathinam R, Berrier A and Alahari SK: Role of Rho GTPases and their regulators in cancer progression. Front Biosci (Landmark Ed) 16: 2561-2571, 2011. 